\title{
REVIEW
}

\section{The transformative impact of extracellular vesicles on developing sperm}

\author{
Michael P Rimmer¹, Christopher D Gregory² and Rod T Mitchell1 \\ 1MRC Centre for Reproductive Health, Queens Medical Research Institute, University of Edinburgh, Edinburgh, UK \\ ${ }^{2}$ Centre for Inflammation Research, Queens Medical Research Institute, University of Edinburgh, Edinburgh, UK
}

Correspondence should be addressed to M P Rimmer or R T Mitchell: Micahel.Rimmer@ed.ac.uk or Rod.Mitchell@ed.ac.uk

\begin{abstract}
Objective: To review the role of extracellular vesicles (EVs) released from the male reproductive tract and their impact on developing sperm. We discuss how sperm exiting the seminiferous tubules, although developmentally mature, require further modification. Acquisition of various functions including increased motility, transfer of cargoes and ability to undertake the acrosome reaction is mediated through the interaction between sperm and EVs.

Methods: A review of the literature identified that EVs are released from different portions of the male reproductive tract, notably the epididymis and prostate. These EVs interact with sperm as they pass from the seminiferous tubules to the epididymis and vas deferens prior to ejaculation.

Results: EVs are small lipid-bound particles carrying bespoke RNA, protein and lipid cargoes. These cargoes are loaded based on the state of the parent cell and are used to communicate with recipient cells. In sperm, these cargoes are essential for post-testicular modification.

Conclusions: Interactions between developing sperm and EVs are important for the subsequent function of sperm. Prior to ejaculation, these interactions confer important changes for the post-testicular modification and development of sperm. Little is known about the interaction between EVs from the testes and the spermatogonial stem cell niche or developing sperm within the seminiferous tubules. However, the numerous roles of EVs in the post-testicular modification of sperm have led many to suspect that they may also play important roles in developing sperm within the testes.
\end{abstract}

\section{Lay summary}

Sperm are crucial for successful fertility. In order to do this, they must be able to swim a large distance to meet the egg in the female reproductive tract and fertilise it. Once released from the testes, sperm may appear to be fully developed, but this is not the case. Several important modifications are required in order for them to swim and fertilise an egg. These modifications are carried out by sending sperm small packages from other cells which contain messages and cargo. We discuss the release of these small packages along with different parts of the male reproductive tract and how they change the way sperm behave and function. This article reviews the literature and known functions of these packages called extracellular vesicles, which are released by the male reproductive tract and modify sperm, transforming their function, before they are ejaculated.

Key Words: - extracellular vesicles $\quad$ male reproductive tract $\quad$ prostasomes $\quad$ epididymosomes $\quad$ fertility

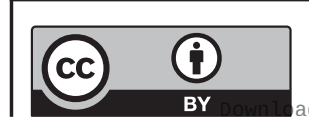




\section{Introduction}

\section{Extracellular vesicles - an overview}

Extracellular vesicles (EVs) are a heterogeneous population of small, cell-derived particles, encapsulated by a lipid bilayer. They are secreted by all cell types with wide-ranging functions in both health and disease (Yáñez-Mó et al. 2015). Once secreted into the extracellular matrix, they are termed as 'EVs' and are unable to replicate (Mause \& Weber 2010). Similar to their cell of origin, they express numerous cell surface ligands, in particular, major histocompatibility complex (MHC) molecules (Synowsky et al. 2017). The expression of 'self' peptides on these MHC molecules makes EVs immunologically inert and, therefore, capable of being widely distributed within the body. Their presence has been reported in all body fluids including blood, urine, cerebrospinal fluid, salvia, breast milk, semen and tears (Pisitkun et al. 2004, Keller et al. 2007, Mathivanan et al. 2010, Baranyai et al. 2015, Gui et al. 2015, Höög \& Lötvall 2015, Riches et al. 2016). It is through their widespread distribution and evasion of the immune system which means they are capable of reaching tissues, remote from their cell of origin to mediate their effects. This is perhaps best demonstrated by their role in developing the premetastatic niche (Guo et al. 2019).

The study of EVs is a rapidly evolving field. First reported in the 1980s, EVs secreted from the reticulocytes of sheep were initially thought to be a means of waste excretion from cells (Johnstone et al. 1987). It is now appreciated that this is far from the case, and EVs carry unique and biologically active cargoes including nucleic acids, lipids, proteins and metabolites. Furthermore, loading of these cargoes into EVs is highly ordered, resulting in some being loaded at concentrations several orders of magnitude greater than that of the parent cell (Turchinovich et al. 2019, Vasconcelos et al. 2019). The precise mechanisms which regulate $\mathrm{EV}$ cargo loading are yet to be elucidated. However, it is in part influenced by the health and state of the parent cell (Han et al. 2019, O'Neill et al. 2019). This variable expression of cargoes implies a highly coordinated process through which cells regulate the messages they transmit to other cells through EVs (Valadi et al. 2007).

EVs are extremely diverse in their size, function and biogenesis; it is due to this diversity that attempts to classify them that have often been met with substantial limitations (Witwer \& Théry 2019). Discussions regarding their characterisation and classification have resulted in a consensus statement, to outline minimum requirements in studies reporting on EVs (Théry et al. 2018). The interaction between cells and EVs broadly occurs through one of four possible pathways: (i) interaction with cell surface ligands; (ii) fusion with the cell membrane and release of cargo into the cell; (iii) endocytic uptake and transport to lysosomes or; (iv) endocytic uptake and transport to specific regions within the cell (Rappa et al. 2017), outlined in Figs 1 and 2.

\section{EVs and the male reproductive tract}

Although EVs are now known to have numerous significant physiological functions in many different organ systems, one area in which our understanding of EVs is especially lacking is the development and function of the male reproductive tract. Spermatogonial stem cells within the testis differentiate and mature into sperm within the seminiferous tubules, from puberty and throughout adulthood. As sperm leave the testes and enter the epididymis, they undergo further important changes, many of which are mediated by the uptake of EVs. In particular, EVs from the epididymis and prostate gland interact with sperm during their transition, conferring numerous modifications and gain of function (MartinDeLeon 2006, Griffiths et al. 2008, Park et al. 2011, Alasmari et al. 2013). Despite the known roles of EVs in the postpubertal maturation of sperm, the presence and potential role of EVs in the foetal or pre-pubertal testis has yet to be reported.

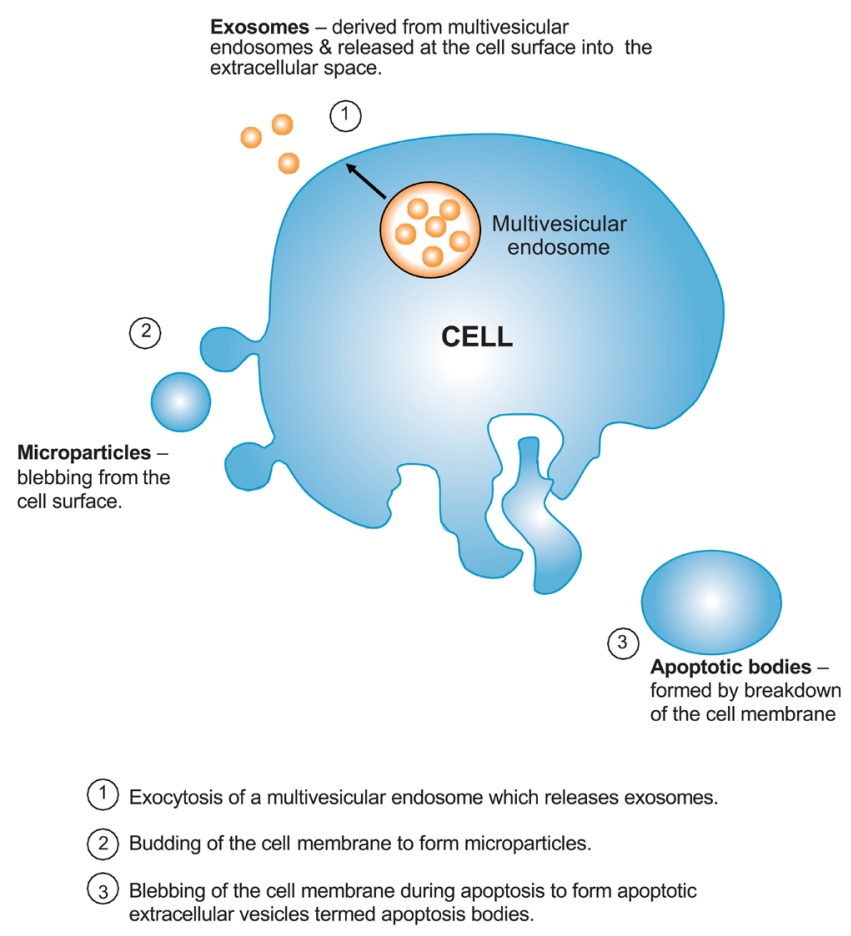

Figure 1 Biogenesis of extracellular vesicles within cells. 


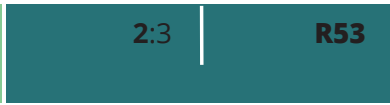

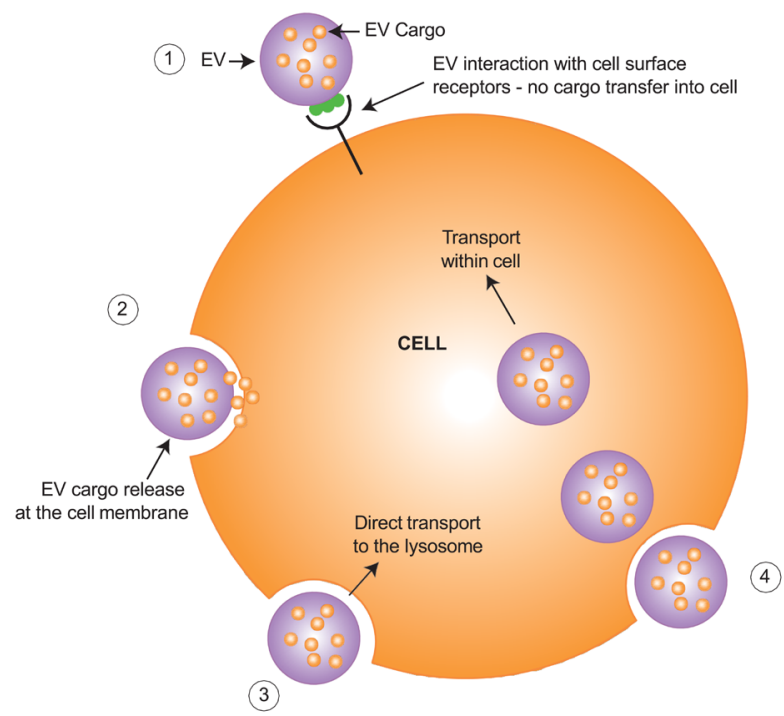

EV Interaction with cells

(1) Ligand binding of $\mathrm{EV}$ with cell surface receptors (the EV does not enter the cell).

(2) Interaction between the EV and cell surface membrane with release of EV cargo into the cell.

(3) Endocytic uptake of the EV by the cell and transport directly to a lysosome where it is broken down.

(4) Endocytic uptake of the EV by the cell and transport to a specific region within the cell.

Figure 2 The interaction between EVs with recipient cells.

Here, we review current knowledge of the impact of EVs in the adult male reproductive tract, in particular, their vital role in sperm development and maturation. We highlight how, without the uptake of EVs from the male reproductive tract, aberrant sperm maturation may occur, leading to poor reproductive outcomes. Finally, we consider the unexplored areas in which EVs may play important roles in the male reproductive tract, drawing parallels between other organ systems and physiological roles played by EVs.

\section{Overview of the development of the adult male reproductive tract}

During the 5th week of human embryonic development, the testes develop from bipotential gonads and undergo a series of genotypic and phenotypic changes, involving migration of primordial germ cells and establishment of the germ cell niche (Nef et al. 2019). Accessory organs to the reproductive tract such as the prostate, seminal vesicles and urinary tract also develop during this time, forming the urogenital system. During foetal life, the testes descend from the abdominal cavity into the scrotum, through the inguinal canal and provide a highly regulated environment in which developing germ cells mature into functional sperm (Marty et al. 2003).

Normal germ cell maturation and function are critical for future reproductive success. During early embryonic
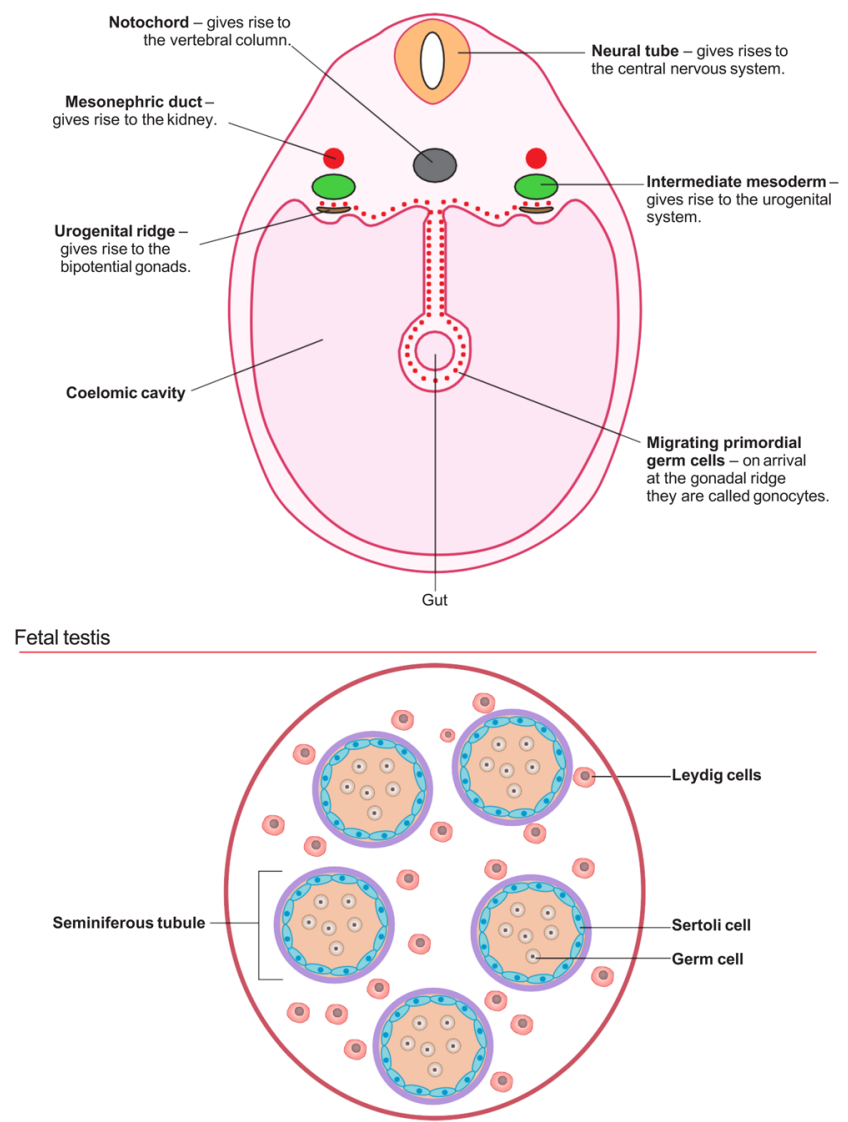

Figure 3 The developing urogenital system: week 4-5.

development, primordial germ cells migrate from the coelomic epithelium to the developing testis, outlined in Fig. 3. On their arrival, they are termed as 'gonocytes', the precursors to spermatogonial stem cells. During foetal and early postnatal life, gonocytes undergo a transition into spermatogonia. The transition from gonocyte to spermatogonia establishes a pool of self-replenishing stem cells within the testis. Throughout childhood, these stem cells are self-renewing with a slow turnover compared to their activity following puberty where surges in hormonal stimulation trigger the initiation of spermatogenesis, resulting in a continuous supply of mature, functional sperm (Marty et al. 2003).

Pubertal changes in boys typically occur around 11 years of age and are driven by increased activity of the hypothalamic-pituitary-gonadal axis (HPG). Key hormones driving pubertal development include luteinising hormone (LH) which stimulates Leydig cells and follicle-stimulating hormone (FSH) which stimulates Sertoli cells (Marty et al. 2003). Both LH and FSH are essential for driving the development of sperm in the testes. The rise in testosterone secreted by LH-stimulated

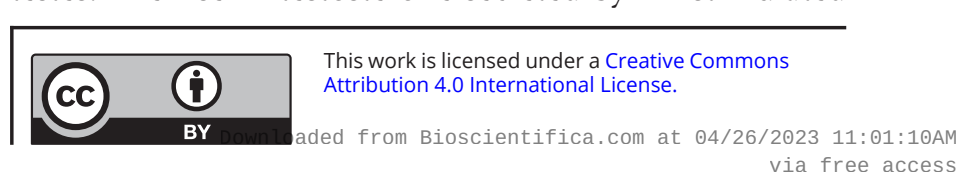


Leydig cells results in the development of secondary sexual characteristics. Within the testis, this rise in testosterone supports spermatogenesis, the differentiation of spermatogonial stem cells into sperm, a continuous process that takes around 74 days.

Spermatogonial stem cell development and subsequently sperm maturation occur in waves, in the highly regulated environment of the seminiferous tubules and spermatogonial stem cell niche (Kostereva \& Hofmann 2008). Seminiferous tubules within the testes converge into the rete testis, draining into the efferent ducts of the epididymis (Clement \& Giuliano 2015a). Despite being morphologically mature, sperm in the rete testes and proximal epididymis are functionally immature and poorly motile.

Within the epididymis, sperm are transformed gaining numerous functions, many of which are mediated by cargo transported to sperm by EVs. These EV-mediated functions include forward motility, zona pellucida binding and the ability to fertilise an oocyte (Martin-DeLeon 2006, Griffiths et al. 2008, Sullivan 2016a). Following their transit through the epididymis, sperm enter the vas deferens, anastomosing with the prostatic duct and seminal vesicle ducts, prior to ejaculation (Clement \& Giuliano 2015b).

\section{Release of extracellular vesicles from the male reproductive tract}

\section{Epididymosomes}

Epididymosomes like other EV populations show high levels of heterogeneity, and two distinct sub-populations have been reported in bovine models. The first is smaller and CD9-positive and fuses with sperm via their tetraspanin domains, while the larger is CD9-negative and contains higher levels of epididymal sperm-binding protein 1 (ELSPBP1) (Frenette et al. 2010, Caballero et al. 2013, Grigor'Eva et al. 2017). These EVs are similar in morphology to other EVs of the reproductive tract and are released from the epididymal epithelium through apocrine secretion by the principal cells of the epithelium (Hermo \& Jacks 2002, Sullivan \& Saez 2013).

The epididymis is a tightly coiled tube on the surface of the testis, conveying sperm from the seminiferous tubules to the ductus deferens, where it joins with the excretory ducts of the seminal vesicles. It has numerous roles including storage, maturation, transport of sperm to the ejaculatory duct and removal of defective sperm. This post-testicular maturation ensures the production of a homogeneous population of sperm. Failure to undergo this transformation produces sperm incapable of fertilising an oocyte (Caballero et al. 2010). To mediate these changes, the blood epididymis barrier (BEB) forms a unique and highly regulated microenvironment, shielding the developing sperm from the immune system through tight junctions which limit the passage of immune cells from the blood. A significant number of these changes to sperm function are mediated through the secretion of various molecules from the epididymis, many of these being transported in EVs termed 'epididymosomes' (Sullivan 2016b).

Proteomic analysis of human epididymosomes collected during vasectomy identified 146 proteins that differed from that of seminal fluid EVs (Thimon et al. 2008). This included enzymes, adhesion, structural and trafficking molecules, but also several with unknown functions. Similar findings were also identified from a bovine model that demonstrated only half the proteins identified in caudal and caput epididymosomes were common to both, in addition to noticeable differences in size (Girouard et al. 2011). The cargo of epididymosomes which varies between the epididymal fluid, caudal and distal epididymosomes, is suggestive of differential cargo loading (Girouard et al. 2011). Once released into the epididymal fluid, epididymosomes interact with sperm transitioning through the epididymis (Schwarz et al. 2013).

Proteomic analysis of mouse epididymosomes also identified segment-to-segment variation; of 1640 proteins identified, 146 were differentially expressed between caput and corpus, while 344 were differentially expressed between corpus and cauda (Nixon et al. 2019). Further examination of the protein cargo of epididymosomes in domestic cats, comparing normospermic and teratospermic animals undergoing orchidectomy, identified both common and differentially expressed proteins. EVs isolated from the epididymal caput, corpus and cauda were examined and revealed over 3008 common proteins within EVs related to motility, zona pellucida binding and the acrosome reaction including sorbitol dehydrogenase, hexokinase 1 , acrosin, and zona pelucida binding protein (ZPBP) 1 and 2, to name but a few (Rowlison et al. 2020). Analysis of the function of these proteins indicated roles in intracellular transport, signalling, metabolism, enzyme and cellular processes, similar to those reported by Gatti et al. and Thimon et al. Despite similarities between samples, 98 proteins were differentially expressed between normospermic and teratospermic cats, with 7 showing significantly reduced expression in the caudal segment. One protein of particular interest with reduced expression is ZPBP-1, whose function allows sperm to penetrate the zona pellucida and fertilise

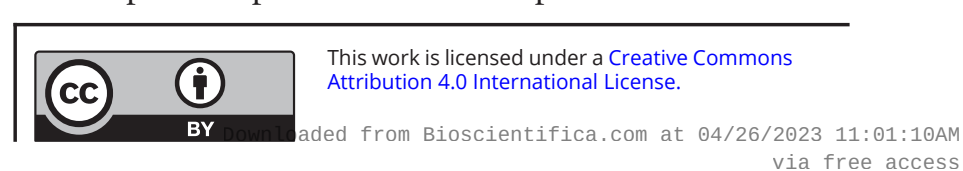


an ovum. Reduced EV-mediated transfer of ZPBP-1 to sperm may in part lead to reduced fertility associated with teratospermia (Rowlison et al. 2020).

Although morphologically 'normal', sperm exiting the seminiferous tubules are functionally immature and require further interaction with EVs and uptake of their cargoes. These cargoes are essential for sperm to undergo further modification to undertake their basic physiological function of traversing the female reproductive tract and fertilising an oocyte.

\section{Role of epididymosomes on sperm maturation}

Epididymosomes, like other EVs within the reproductive tract are highly heterogeneous and are important for the development and maturation of sperm. The protein ELSPBP1 was first identified in humans and canines as a sperm-binding protein (SPB) and originates from the epididymis (D'Amours et al. 2012b). Its structure is similar to the family of SBPs containing four tandemly arranged fibronectin type 2 molecules(Saalmann et al. 2001). SBPs bind to sperm following ejaculation and facilitate numerous functions including capacitation and motility (Ekhlasi-Hundrieser et al. 2007, Plante et al. 2016). In recent years, the presence of ELSPBP1 has been identified in epididymosomes from several other species. Its precise function, however, remains unexplained.

Contents of epididymosomes differ from the luminal fluid in which they are suspended as well as the cells from which they are released (Girouard et al. 2011). Interestingly, EVs released by the proximal epididymis carry a different subset of miRNA cargos than EVs released from the distal epididymis (Belleannée et al. 2013a). The differential expression of $>5$ or $<5$-fold change of 83 miRNAs was reported between the epididymal epithelium and epididymosomes, while variation in the miRNA profile between caput and caudally released epididymosomes demonstrated 178 miRNAs with $>2$ or $<2$-fold changes in expression (Belleannée et al. 2013a). Molecules exchanged between epididymosomes and sperm include sperm adhesion molecule 1 (SPAM1) (Martin-DeLeon 2006, Griffiths et al. 2008), glioma pathogenesis-related 1-like protein 1 (GliPr1L1) (Caballero et al. 2012) and metalloproteases (Oh et al. 2009); all of which play a role in fertilisation. Numerous other proteins transferred by epididymosomes to sperm appear to have roles including capacitation and motility such as the proto-oncogene tyrosine-protein kinase Src (cSrc) and macrophage migration inhibitory factor (MIF) (Frenette et al. 2002, Eickhoff et al. 2004, Krapf et al. 2012). Protection of sperm DNA from oxidative stress is conveyed through the transfer of non-conventional glutathione peroxidase 5 (GPX5) (Chabory et al. 2009), while the transfer of Liprin $\alpha 3$ is an important component for sperm to undergo the acrosome reaction (Gervasi \& Visconti 2017). Despite the extensive understanding of some cargos delivered to sperm through epididymosomes, not all have a clearly defined function, for example, methylmalonate-semialdehyde dehydrogenase (MMSDH) (Suryawanshi et al. 2012).

Evidence supporting the role of epididymosomes in sperm maturation can be drawn from the changing morphology and cargo of epididymosomes released from different segments of the epididymal lumen as well as changes within sperm (Trigg et al. 2019). This is correlated with sperm acquisition of function including motility and capacity to fertilise an ovum (Sullivan 2016a). Epididymosomal cargo incorporated into sperm is transported to specific areas within the sperm based on the region of the epididymis from which they are secreted (Sullivan et al. 2007, Nixon et al. 2019). These molecules have roles in sperm motility such as sperm migration inhibitory factor which is transported to the fibres of the flagellum (Eickhoff et al. 2001, Eickhoff et al. 2006). Molecules regulating binding to the zona pellucida, for example, P26h/P25b, are transported to the plasma membrane, overlying the acrosome (Légaré et al. 1999).

Although the specific role of epididymosome miRNA on future offspring in humans is unclear, it is well established that miRNAs within epididymosomes released by the proximal epididymis alter the gene expression of epididymal cells in the distal portion (Belleannée et al. 2012, Belleannée et al. 2013b). The impact this has on subsequent epididymosome release and their cargo is yet to be determined.

Proteomic analysis from a bovine model demonstrated that only half the proteins identified in caudal and caput epididymosomes were common to both, in addition to notable differences in size (Girouard et al. 2011). The cargo of epididymosomes which varies between the epididymal fluid, caudal and distal epididymosomes, is suggestive of differential cargo loading (Girouard et al. 2011). Once released into the epididymal fluid, epididymosomes interact with sperm transitioning through the epididymis (Schwarz et al. 2013).

\section{Elimination of defective sperm}

Although the precise function of ELSPBP1 within EVs is unknown, its presence within sperm is the characteristic of sperm that have died, prior to ejaculation. It has been

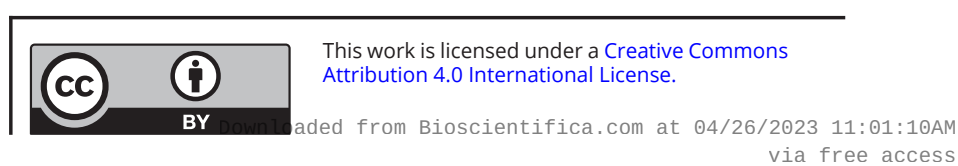


identified in sub-fertile bulls, and further analysis has shown it to be present only in the dead sperm (D'Amours et al. 2012a). Although the expression of ELSPBP1 can be used to characterise dead sperm within the epididymis, its presence was only identified within a subset of dead sperm in the proximal epididymis, but all dead sperm in the distal epididymis (D'Amours et al. 2012b). This finding is suggestive of secretion by the epididymis and uptake of ELSPBP1 by sperm as they transit through the epididymis. Discussions as to its possible function have led some to speculate that its presence within dead sperm may be protective to live sperm (D'Amours et al. 2012b), similar to fibrinogen-related protein (FGL2), another epididymal protein associated with non-viable sperm (Olson et al. 2004). FGL2 forms a protective coat around non-viable sperm, shielding viable sperm from the release of deleterious enzymes (D'Amours et al. 2012b).

\section{EV-mediated changes to offspring}

Modification of RNA within sperm, through external stimuli, can alter paternally inherited characteristics in the offspring such as insulin sensitivity (Gapp et al. 2014, Chen et al. 2016), although the ability for epididymal EV-mediated RNA to confer these epigenetic modifications was only recently proven (Maciel \& Mansuy 2019). Chan et al. identified that paternal environmental stressors were conveyed to developing sperm by epididymal EVs, mediating post-testicular germline modifications to sperm. This was further studied in an in vitro model using corticosterone to mimic physiological stress, which altered miRNA and protein cargoes of EVs. Incubation of these EVs with sperm and subsequent intracytoplasmic sperm injection to oocytes led to transcriptomic alterations in both placental and brain tissue in developing mouse embryos (Chan et al. 2020).

At present, the specific role of epididymosomal cargoes on future offspring in humans is unclear. The ability for proximal epididymal miRNA cargoes to alter gene expression on the distal epididymis is well established and highlights the potential for these molecules to have, as yet, unidentified impacts on the offspring (Belleannée et al. 2012, Belleannée et al. 2013b).

\section{Prostasomes and seminal fluid extracellular vesicles}

The prostate gland is the largest of the male reproductive accessory organs and sits at the base of the urinary bladder. Secretions from the prostatic epithelium into the prostatic ducts make up to one-sixth of the ejaculate which then mixes with sperm from the vas deferens. The identification of EV-like storage vesicles within the prostate, termed 'prostasomes', provides tentative evidence of their generation from a similar biogenesis pathway to that of exosomes, formed within the multivesicular endosome of the cell.

Prostasomes were first reported by Ronquist et al. in 1978 and described as submicron membrane-bound secretory granules released by the acinar cells of the prostate gland (Ronquist et al. 1978a,b). They form a part of the numerous fractions of EVs within semen as they mix with those from the epididymis and other areas of the reproductive tract (Höög \& Lötvall 2015, Jodar et al. 2017).

Like other EV populations, prostasomes are heterogeneous, ranging in size from $40-500 \mathrm{~nm}$ (Ronquist et al. 1978a,b). Their characterisation has led to the identification of two distinct sub-populations based on morphology; one larger cohort and one smaller, more electron-dense cohort. The formation of prostasomes appears to differ from that of epididymosomes. Their assembly has been visualised within the apical region of the cell, where the golgi apparatus is most abundant. The size profile of prostasomes is similar to storage vesicles within the prostate epithelium, leading to speculation that these storage vesicles may be prostasomes yet to be released or share a similar biogenesis pathway (Ronquist $\&$ Brody 1985). Further imaging has identified similarities between storage vesicle production within the prostate and multivesicular bodies, a site of EV production within cells (Sahlén et al. 2002). Surface markers of prostasomes, albeit produced from a prostate cancer cell line (PC-3), are enriched with several multivesicular bodies and EV markers including hepatocyte growth factor-regulated tyrosine kinase substrate (HGS), lysosomal-associated membrane protein 1 and 2 (LAMP1 and LAMP2), and tumour susceptibility gene 101 (TSG101) (Llorente et al. 2004, Llorente et al. 2007). Despite similarities between prostasomes and prostate storage vesicles, it has never been conclusively demonstrated that storage vesicles observed within the prostate are the precursors to prostasomes released into the extracellular environment.

\section{Role of prostasomes on sperm maturation}

Prior to the interaction between sperm and prostasomes or seminal fluid EVs, sperm undergo differentiation and maturation within the highly regulated and immuneprivileged environment of the testes. This is essential for their development. Following ejaculation, however,

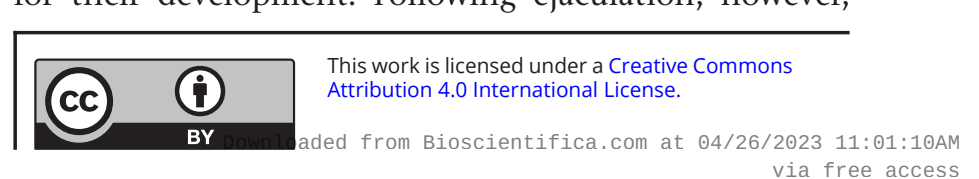


further modifications are required for the successful fertilisation of an oocyte, many of which are mediated through prostasomes.

The interaction of EVs with sperm following ejaculation and transfer of $\mathrm{Ca}^{2+}$ highlights one of their many roles in post-testicular modification to sperm. Although sperm used in intracytoplasmic sperm injection techniques are extracted from the epididymis and capable of fertilising an oocyte, they are artificially introduced to the cytoplasm. This bypasses the need to traverse the female reproductive tract and carry out the acrosome reaction, both essential prerequisites for successful fertilisation. Examination of the EVs present within semen revealed a diverse mixture of individual vesicles but also multifaceted structures which tentatively points to the release of EVs from other portions of the reproductive tract which are yet to be characterised (Höög \& Lötvall 2015). This heterogeneity of EVs within the seminal fluid, the origins of which may be poorly characterised, means the function of these EVs may not be exclusively attributed to a subset of known EVs, such as prostasomes.

Since their discovery, the potential functions of prostasomes and seminal fluid EVs have been widely investigated. Sperm ejaculated into the female reproductive tract, although developmentally mature, still needs to undergo further modification to acquire fertilising potential (Bailey 2010). These processes are collectedly termed as 'capacitation' and include zona pellucida binding, the acrosome reaction and the potential to interact with the oocyte plasma membrane. Unsurprisingly, several seminal fluid EV functions have been identified, the most significant of which is their ability to directly fuse with sperm, similar to epididymosomes (Kravets et al. 2000). Unlike epididymosomes, however, the interaction between sperm and seminal fluid EVs appears to occur following ejaculation as they interact in the female reproductive tract and are discussed in more detail below (Aalberts et al. 2014).

Analysis of the composition of seminal fluid EVs comparing asthenozoospermic and normozoospermic patients identified the differential expression of the protein transient receptor potential vanilloid subfamily member 6 (TRPV6) (Lin et al. 2019). TRPV6 is an epithelial $\mathrm{Ca}^{2+}$ channel, regulating intraluminal $\mathrm{Ca}^{2+}$, and knockout of the TRPV 6 gene has been shown to disrupt $\mathrm{Ca}^{2+}$ absorption within the epididymal epithelium resulting in higher intraluminal $\mathrm{Ca}^{2+}$ (Weissgerber et al. 2012). In addition to disrupted $\mathrm{Ca}^{2+}$ regulation, decreased levels of TRPV6 within seminal fluid EVs and spermatozoa were associated with asthenozoospermia and reduced fertilization capacity (Weissgerber et al. 2012, Lin et al.
2019). Given our understanding of the importance of $\mathrm{Ca}^{2+}$ regulation in sperm motility, lower levels of TRPV6 within EVs and reduced EV-mediated transfer of TRPV6 may play an important role in conferring motility to developing sperm.

\section{Extracellular vesicles and male gamete function}

The interaction of sperm and seminal fluid EVs occurring only after ejaculation means the majority of their association and transfer of cargo occurs in the lower female reproductive tract (Arienti et al. 2004). This may be why interactions between sperm and seminal fluid EVs favour a slightly acidic $\mathrm{pH}$, as demonstrated in in vitro studies using equine sperm (Aalberts et al. 2013), an environment similar to the female reproductive tract. Interestingly, these interactions vary based on $\mathrm{pH}$, with EVs binding to the mid-piece of sperm in an acidic environment but the head of sperm in a neutral pH (Arienti et al. 1997, Park et al. 2011). This interaction is associated with increased sperm survival in the lower female genital tract and enables sperm to pass through the cervical mucus and traverse the great distance to the fallopian tubes to fertilise on oocyte (Ronquist \& Nilsson 2004). Sperm within the ejaculate are not yet fully functional and must first undergo capacitation (Fraser 2010). The abundance of protamines within sperm which replace histones during spermatogenesis means they are unable to synthesise proteins and rely on interaction with the external environment for further modification, such as interaction with EVs (Samanta et al. 2016).

Capacitation refers to a process which describes the functional maturation of sperm. These changes include increased motility and potential to bind to the zona pellucida via receptors on the sperm head (Aalberts et al. 2014). These processes are driven by protein kinase $C$ activity within sperm and are stimulated by cAMP. Delivery of cAMP within prostasomes leads to higher levels of cAMP within sperm (Fraser 2010).

In addition to cAMP and cargoes to undertake capacitation, prostasomes deliver other essential cargo to sperm, notably cyclic adenosine diphosphoribose and $\mathrm{Ca}^{2+}$ signalling machinery (Park et al. 2011). $\mathrm{Ca}^{2+}$ regulation within sperm is essential for its motility and interaction with the oocyte when carrying out the acrosome reaction (Park et al. 2011, Alasmari et al. 2013). Despite the transfer of epidydimal cargoes such as ADAM-7, MIF and aldose reductase which promote motility, prostasomes transfer their own unique cargoes to further promote sperm motility.

The impact of prostasomes on sperm is dynamic (Aalberts et al. 2014). Despite evidence suggesting the 
interaction between sperm and prostasomes increase the activity of sperm, prostasomes also confer inhibitory changes. In particular, a reduction in levels of tyrosine phosphorylation negatively impacts capacitation; however, this has only been demonstrated in one study (Pons-Rejraji et al. 2011). Prostasomes are also reported to reduce motility through the delivery of $\mathrm{Zn}^{2+}$ ions. The presumption that $\mathrm{Zn}^{2+}$ resides within prostasomes is supported by lower levels of $\mathrm{Zn}^{2+}$ in prostasome-free semen samples. However, this observation does not definitively confirm the presence of $\mathrm{Zn}^{2}$ within prostasomes (Vivacqua et al. 2004).

Interestingly, the cargo delivered by prostasomes to sperm is predominantly to the neckpiece of the sperm, as opposed to the head and suggests EVs are the targeted specific regions of the sperm (Park et al. 2011). It should be noted that altered prostasome binding to different regions on the sperm may be due to expression of alternative ligands by the sperm and not due to changes to the binding potential of the prostasome.

As well as their interactions with EVs from the male reproductive tract, in vitro models have demonstrated uptake of endometrial EVs by spermatozoa (Murdica et al. 2020). Fluorescently labelled EVs derived from cultured endometrial cells in the proliferative phase demonstrated an increased uptake by sperm compared to their secretory phase counterparts. Uptake of secretory phase EVs was then shown in increased capacitation potential within sperm and likely reflects one of the many dynamic interplays between the male gamete and female reproductive tract in preparation for fertilisation and subsequent implantation of an embryo (Martin-DeLeon 2016, Murdica et al. 2020).

\section{Proteomic analysis}

Proteomic analysis by Utleg et al. identified over 139 proteins using mass spectrometry of prostasome cargoes. However, these were obtained from EVs within seminal fluid and may represent a heterogeneous EV population. Some were specific to the prostate, such as prostate-specific antigen (PSA) and prostatic acid phosphatase (PAP), but many had not been previously identified within the seminal fluid EVs (Utleg et al. 2003). Analysis of these proteins' functions demonstrated that the most abundant group was enzymes, followed by transport and structural proteins. These findings suggest prostasome cargo may have the potential to influence a cell's metabolic state. Additional functions of seminal fluid EVs contents include PSA and peptide hydrolases which liquefy semen and degrade seminal proteins, respectively (Utleg et al. 2003).
Structural and transport proteins such as annexins, actin and profilin, which have important functions in calciumbinding, cell structure and actin-binding have also been identified (Utleg et al. 2003). Other molecules within seminal fluid EVs include G-binding, chaperone and signal transduction proteins (Utleg et al. 2003, Burden et al. 2006).

Although 684 proteins were identified in both cohorts of EVs, 539 were exclusively detected within large EVs and 7 in small EVs. Assessment of the functions of these proteins revealed distinct molecular functions between large and small EVs including cell growth, apoptosis, cell communication, metabolism and signal transduction (Zhang et al. 2020). A similar study by Yang et al. also reported numerous proteins within seminal plasma EVs characterised by mass spectrometry. To be confident that the proteins identified originated from EVs, both sperm cell lysate and EV depleted seminal plasma were used as controls. Molecular and biological functions identified by gene enrichment analysis include catalytic activity, GTPase activity, metabolism and cell growth and maintenance (Yang et al. 2017).

Although a heterogeneous source of EVs, proteomic analysis of seminal fluid EVs was undertaken by Lin et al. comparing asthenozoospermic and normozoospermic patients. Differential expression of 11 upregulated and 80 downregulated proteins was identified in asthenozoospermic patients from 3699 uniquely identified proteins. Gene ontology analysis of these proteins demonstrated roles in transcription, proteolysis, metabolism, protein binding, intracellular transport and autophagy (Lin et al. 2019). Impaired ability of sperm to carry out these essential roles clearly demonstrates how sperm with impaired cargo transfer from EVs will fail to develop fully, and patients identified clinically as asthenozoospermic.

As discussed earlier in this review, the proteomic analysis of human epididymosomes obtained during a vasectomy identified 146 individual proteins which differed from proteins identified within seminal fluid EVs (Thimon et al. 2008). These proteins had numerous functions which included enzymes, adhesion, structural and trafficking molecules, but also several whose functions have not yet been characterised. Despite the numerous functions epididymosomes play in sperm maturation, for several of these proteins it has yet to be elucidated if they are transferred to sperm, or lead to their modification in any meaningful way.

Due to procedural limitations in this study, in obtaining epididymosomes specifically from the patients' caput, corpus and caudal epididymis, Thimon et al. 
compared mRNAs identified from their patient cohort to known mRNAs from published datasets. mRNAs from 19 proteins were differentially expressed and were suggestive of EVs secreted predominantly from the caput $(n=13)$ but also the corpus $(n=3)$ and cauda $(n=3)$ of the epididymis (Thimon et al. 2008).

A similar study by Gatti et al. also studied the protein composition of epididymosomes in rams identifying the distinct differences between EVs obtained from caudal fluid, seminal plasma and sperm extracts. Numerous functions of these proteins were reported, as with the study by Thimon et al., including transport proteins, enzymes, cytoskeletal proteins and vesicle-associated proteins (Gatti et al. 2005). Analysis of EVs from different segments of the epididymis identified not all were secreted equally with proteins such as phosphodiesterase E-NPP3 predominantly secreted from the caudal epithelium (Gatti et al. 2005).

\section{EV interaction with the immune system}

The interaction between EVs and the immune system is widely characterised, with an overview of several of these interactions both in the male and female reproductive tract discussed below (Poon et al. 2018, Mittal et al. 2020, Zhou et al. 2020).

Of the many interactions within the male reproductive tract, of particular interest is CD47 expressed both by large prostate EVs and also by tumour cells. CD47 modulates the immune system and acts as an anti-phagocytic signal to macrophages (Chao et al. 2019). EV-mediated transfer of CD47 to sperm may also confer some protection from macrophage phagocytosis within the female reproductive tract (Zhang et al. 2020). This protection through the impaired immune response of macrophages may be one of the many roles seminal fluid plays in the female reproductive tract to allow sperm to survive to fertilise an oocyte. Further $\mathrm{EV}$ interactions with the immune system have been identified by prostasomes, a component of seminal fluid EVs which both impaired lymphocyte proliferation and impaired neutrophil functions (Skibinski et al. 1992).

Modulation of the immune response by EVs within seminal fluid continues once sperm enter the female reproductive tract and plays several roles in adapting the maternal immune response both to sperm and the developing semi-allogenic conceptus (Tannetta et al. 2014). Interaction between CD48 expressing prostasomes and uterine natural killer (uNK) cells showed both a reduction in the uNK activating receptor CD244 but also reduced uNK activity and expression of interferon-gamma (Tarazona et al. 2011). The combination of these effects may be protective to sperm traversing the female reproductive tract and subsequent embryo implantation. In addition to CD48 expression, prostasomes expressed CD59 and were protective to sperm from the complement system of the female reproductive tract (Rooney et al. 1993). In a porcine model, the interaction between seminal fluid EVs and the endometrium demonstrated EV-mediated alteration to the transcriptomeofbothimmunoregulatoryandinflammatory pathways (Bai et al. 2018). In particular, downregulated $T$ cell differentiation is suggestive of EV-mediated protection to sperm within the female reproductive tract, while changes to inflammatory pathways may be a crucial aspect of the highly regulated window of embryo implantation (Ochoa-Bernal \& Fazleabas 2020). Although seminal fluid, for which EVs are a component, mediates changes in both gene expression and inflammation, the impact of these changes has not been clearly attributed to EVs (Robertson et al. 2009, Sharkey et al. 2012).

\section{Lesser characterised EVs of the male reproductive tract}

Despite the extensive and comprehensive characterisation of EVs and their various functions from the epididymis and prostate, other regions of the male reproductive tract have yet to be studied extensively. Herein we discuss the provisional identification of EVs within the vas deferens, testes and the seminal vesicles, outlined in Fig. 4.

\section{Vas deferens-derived EVs}

Following passage through the epididymis, sperm transitions to the vas deferens, which transports sperm stored within the epididymis to the ejaculatory duct and mixes with prostatic and seminal vesicle secretions (Sullivan et al. 2005). Secretions within the epididymis appear to have a role in modifying the environment of sperm cells prior to mixing with the prostate. Little is known about the function of EVs from the vas deferens but it may be possible that their release from this portion of the reproductive tract is limited, although the widespread release of EVs from other tissues suggests that this is unlikely (Manin et al. 1995). However, the mere identification of EVs from the vas deferens is insufficient to conclude that they interact with or modify sperm in any meaningful way.

\section{The testes}

The release of EVs from within the testis, although highly probable given the heterogenous nature of EVs identified within seminal fluid, has yet to be identified in humans.

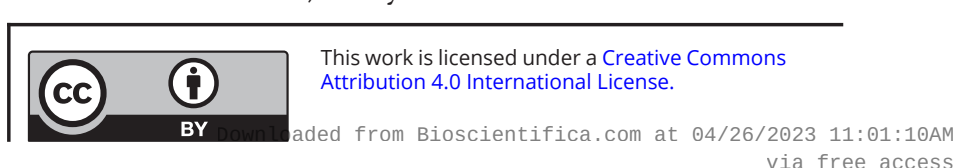




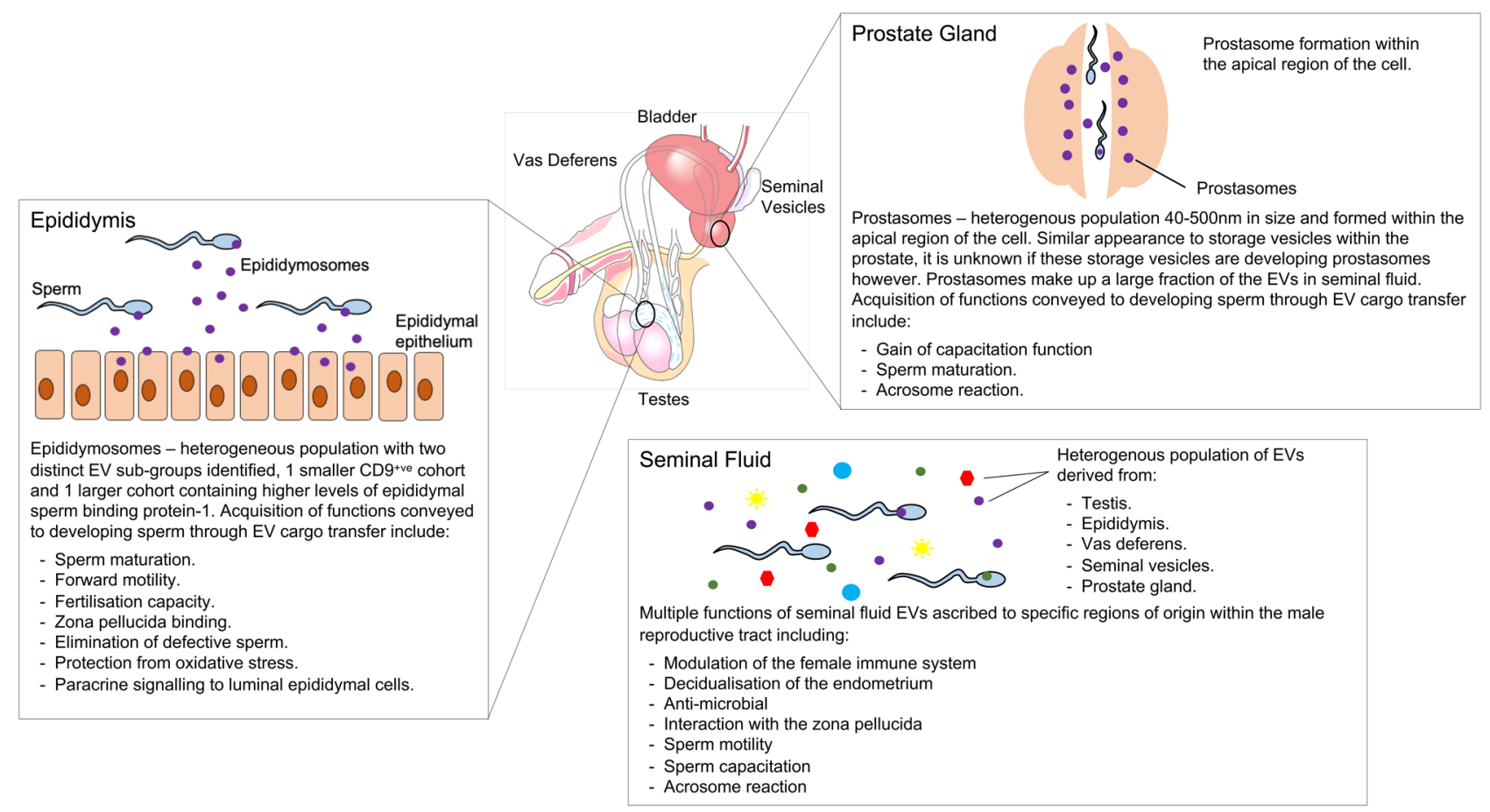

Figure 4 Extracellular vesicles from the male reproductive tract and their known functions.

However, the presence of EVs within the seminiferous tubule, the main site of sperm differentiation within the testis has been reported in turtles. Testis tissue from Chinese soft-shelled turtles, Pelodiscus sinensis, was examined using transmission electron microscopy and immunohistochemistry, identifying vesicle-like structures of a similar profile to exosomes, secreted into the seminiferous tubules (Ahmed et al. 2016). Further work exploring EVs released in the Chinese soft-shelled turtles was carried out using immunohistochemistry and immunofluorescence for the common EV marker CD63 and transmission electron microscopy for multivesicular bodies. Tarique et al. identified numerous CD63 signals within the basal compartment of the seminiferous tubules during early spermatogenesis, while during late spermatogenesis this was identified within the lumen of the seminiferous tubule. This recent finding suggests Sertoli cells within the testis secrete EVs into the seminiferous tubules during sperm differentiation. Given our understanding of the important roles, EVs play in other aspects of sperm development, it is highly plausible that these purported EVs may also play a crucial role in sperm development (Tarique et al. 2020).

\section{Seminal vesicles}

The seminal vesicles are paired secretory glands adjacent to the prostate, lying on the base of the bladder, which secretes fluid rich in fructose and prostaglandins forming part of the ejaculate in which seminal fluid EVs are suspended. Analysis of the different fractions of the ejaculate, notably the prostatic fraction and seminal fluid fraction through centrifugation, revealed the presence of distinct $\mathrm{EV}$ markers. However, markers used to identify prostasomes (CD10, CD13 and CD26) were found to be absent within the seminal fluid pellet which instead contained heat shock protein-70 and CD55, both of which are known EV markers (Sahlén etal. 2010). Electron microscopy of prostate and seminal vesicle tissue demonstrated that EVs, unlike prostasomes, were released as single discrete structures by seminal vesicles rather than stored and secreted within larger secretory granules.

\section{Future perspectives}

The field of EVs has grown rapidly in both an appreciation of their widespread distribution, identification in numerous body fluids and a greater understanding of their role in health and disease. The advent of technologies, not only to characterise EVs in vivo but also to isolate and study them in vitro, has led to significant advances in our understanding of their potential.

Identification of unique cargo within EVs offers new opportunities to develop novel diagnostic tools in order 
to recognise diseases that currently lack sensitive and specific tests. Increasing use of EVs both in science and healthcare, rapidly expanding cataloging of their cargo and falling costs of underlying technologies, will likely remove barriers to the routine use of EVs in healthcare settings as biomarkers to facilitate early disease detection and monitoring in the future.

A new and expanding area in EV research is their use as therapeutic targets, including delivery of therapeutics to previously hard-to-reach tissue. The ability to manipulate EVs either through the artificial incorporation of molecules such as short interfering RNA or modulating their interaction with cells represents a new potential field of clinical therapeutics.

Further work to understand how EVs are targeted or indeed how their surface ligands can be modified either physiologically or artificially represents a significant next step for the field of EV biology. This is of particular importance when characterising the release of EVs in the male reproductive tract, which compared to many other tissues, remains largely unstudied. The migration of primordial germ cells and development and maintenance of the germ cell niche during foetal development bears a striking resemblance to the development of cancer metastasis. A greater understanding of the development of this niche may give important insights as to how it can be preserved from damage and promote future fertility. The role of EVs in the development of a metastatic niche is well established, yet has never been studied in the development of the testicular stem cell niche. Although not in the male reproductive tract, EVs have been reported in the intestinal and haemopoietic stem cells niches (Laurenzana et al. 2018, Oszvald et al. 2020).

Currently, the release of EVs has not been reported in the testis in humans at different stages of development but has been extensively characterised in the epididymis and prostate, in the adult reproductive tract. Identification of EVs released in the foetal and pre-pubertal testis may give insights into the regulation of germ cell development and testicular pathologies across development, in a similar way to the modification of maturing sperm in the adult testis (Maciel \& Mansuy 2019). Developments in the study of EVs released from the pre-pubertal male reproductive tract may lead to a greater understanding of how gonadotoxic exposures (e.g. chemotherapy) lead to lifelong damage to the testes. Furthermore, identification of EVs specific to the development of germ cell neoplasia in situ cells (GCNIS), the precursor for testicular germ cell tumours, may allow early diagnosis and treatment in the pre-malignant stage.

https://raf.bioscientifica.com

https://doi.org/10.1530/RAF-20-0076

(c) 2021 The authors Published by Bioscientifica Ltd
Although their release has only been investigated in the transport and storage components of the adult reproductive tract, EVs from these tissues have a clear and important role in the maturation and transformation of sperm. Failure of sperm to undergo this process and acquisition of new functions, mediated by EVs, leaves them incapable of performing their most essential biological function: traversing the female reproductive tract and fertilisation of an oocyte. Further modifications occur in the female reproductive tract including the adaptation of the female immune response to sperm and preparation of the endometrium for embryo impanation, not covered in this review.

Increasing knowledge regarding EVs is likely to provide exciting opportunities in the future for the development of EV-based diagnostic and therapeutic options. The potential role of EVs as novel vectors for drug delivery has recently been explored with numerous applications in a range of tissues (de Jong et al. 2019). Their use within the reproductive tract to deliver cargoes has only recently been explored. EVs generated from human embryonic kidney cells have been fluorescently labelled and visualised entering boar sperm. Crucially, no detrimental impact on sperm motility, viability and membrane integrity was identified which highlights their potential novel use to deliver cargoes to sperm (Vilanova-Perez et al. 2020). The interaction between sperm and an oocyte may then allow such cargoes to be incorporated into the developing embryo. Given recent developments in our understanding as to how paternal stressors alter EV cargoes with transcriptomic alterations in the offspring (Chan et al. 2020), we anticipate this will become an exciting and rapidly growing area of reproductive medicine.

The understanding of EVs in gamete and embryo development has grown in recent years as EVs identified within follicular fluid have been shown to interact with the developing conceptus (Gervasi et al. 2020, Han et al. 2020). ThisEV-mediated processnotonlyincludescommunication within the same organism but also between paternal EVs and the maternal reproductive tract (Machtinger et al. 2016, Rodriguez-Caro et al. 2019). Delivery of EV cargo to the conceptus has been shown to enhance its development and has led some to speculate their lack of inclusion in current artificial reproductive technology (ART) may in part explain the poor development of some embryos in culture. Specific cargoes delivered to EVs include melatonin which was found to regulate reactive oxygen species in a rabbit model (Qu et al. 2020), while in bovine models follicular fluid EVs trigger granulosa cell proliferation (Hung et al. 2017), a finding also demonstrated in horses (da Silveira 
et al. 2012). Identification of the cargoes which induce these changes may lead to the development of bespoke ART media supplementation to improve the development of embryos in culture.

Despite the numerous advances in our understanding of EVs in the adult male reproductive tract, there is an urgent need for a greater understanding of the roles EVs play in the developing male reproductive tract (Baskaran et al. 2020). Based on the emerging evidence of EVs in sperm maturation and development, there seems little doubt that locally produced EVs will prove to play significant roles.

\section{Declaration of interest}

The authors declare that there is no conflict of interest that could be perceived as prejudicing the impartiality of this review.

\section{Funding}

M P R and R T M are funded by a MRC Centre for Reproductive Health Grant No: MR/N022556/1. R T M is funded by a UK Research and Innovation (UKRI) Future Leaders Fellowship MR/S017151/1.

\section{Author contribution statement}

M P R conceived the idea for the article, undertook the literature search, wrote the manuscript, developed the figures and approved the manuscript for submission. C D G and R T M conceived the idea for the manuscript, undertook editorial changes and approved it for submission.

\section{References}

Aalberts M, Sostaric E, Wubbolts R, Wauben MW, Nolte-'t Hoen EN, Gadella BM, Stout TA \& Stoorvogel W 2013 Spermatozoa recruit prostasomes in response to capacitation induction. Biochimica et Biophysica Acta 1834 2326-2335. (https://doi. org/10.1016/j.bbapap.2012.08.008)

Aalberts M, Stout TA \& Stoorvogel W 2014 Prostasomes: extracellular vesicles from the prostate. Reproduction 147 R1-R14. (https://doi. org/10.1530/REP-13-0358)

Ahmed N, Yufei H, Yang P, Muhammad Yasir W, Zhang Q, Liu T, Hong C, Lisi H, Xiaoya C \& Chen Q 2016 Cytological study on Sertoli cells and their interactions with germ cells during annual reproductive cycle in turtle. Ecology and Evolution 6 4050-4064. (https://doi.org/10.1002/ece3.2193)

Alasmari W, Costello S, Correia J, Oxenham SK, Morris J, Fernandes L, Ramalho-Santos J, Kirkman-Brown J, Michelangeli F, Publicover S, et al. $2013 \mathrm{Ca} 2+$ signals generated by CatSper and $\mathrm{Ca} 2+$ stores regulate different behaviors in human sperm. Journal of Biological Chemistry 288 6248-6258. (https://doi. org/10.1074/jbc.M112.439356)

Arienti G, Carlini E \& Palmerini CA 1997 Fusion of human sperm to prostasomes at acidic pH. Journal of Membrane Biology 155 89-94. (https://doi.org/10.1007/s002329900160)

Arienti G, Carlini E, Saccardi C \& Palmerini CA 2004 Role of human prostasomes in the activation of spermatozoa. Journal of Cellular and
Molecular Medicine 8 77-84. (https://doi.org/10.1111/j.1582-4934.2004. tb00261.x)

Bai R, Latifi Z, Kusama K, Nakamura K, Shimada M \& Imakawa K 2018 Induction of immune-related gene expression by seminal exosomes in the porcine endometrium. Biochemical and Biophysical Research Communications 495 1094-1101. (https://doi.org/10.1016/j. bbrc.2017.11.100)

Bailey JL 2010 Factors regulating sperm capacitation. Systems Biology in Reproductive Medicine 56 334-348. (https://doi.org/10.3109/19396368. 2010.512377)

Baranyai T, Herczeg K, Onodi Z, Voszka I, Modos K, Marton N, Nagy G, Mager I, Wood MJ, El Andaloussi S, et al. 2015 Isolation of exosomes from blood plasma: qualitative and quantitative comparison of ultracentrifugation and size exclusion chromatography methods. PLoS ONE 10 e0145686. (https://doi.org/10.1371/journal. pone.0145686)

Baskaran S, Panner Selvam MK \& Agarwal A 2020. Chapter Four - Exosomes of male reproduction. In Advances in Clinical Chemistry. Ed GS Makowski. Elsevier. (https://doi.org/10.1016/ bs.acc.2019.08.004)

Belleannée C, Calvo E, Thimon V, Cyr DG, Légaré C, Garneau L \& Sullivan R 2012 Role of microRNAs in controlling gene expression in different segments of the human epididymis. PLOS ONE 7 e34996. (https://doi.org/10.1371/journal.pone.0034996)

Belleannée C, Calvo É, Caballero J \& SULLIVAN R 2013a Epididymosomes convey different repertoires of microRNAs throughout the bovine epididymis. Biology of Reproduction 8930. (https://doi.org/10.1095/biolreprod.113.110486)

Belleannée C, Légaré C, Calvo E, Thimon V \& Sullivan R 2013b MicroRNA signature is altered in both human epididymis and seminal microvesicles following vasectomy. Human Reproduction 28 1455-1467. (https://doi.org/10.1093/humrep/det088)

Burden HP, Holmes CH, Persad R \& Whittington K 2006 Prostasomes - their effects on human male reproduction and fertility. Human Reproduction Update 12 283-292. (https://doi.org/10.1093/ humupd/dmi052)

Caballero J, Frenette G \& Sullivan R 2010 Post testicular sperm maturational changes in the bull: important role of the epididymosomes and prostasomes. Veterinary Medicine International 2011 757194. (https://doi.org/10.4061/2011/757194)

Caballero J, Frenette G, D'Amours O, Belleannée C, LacroixPepin N, Robert C \& Sullivan R 2012 Bovine sperm raft membrane associated glioma pathogenesis-related 1-like protein 1 (GliPr1L1) is modified during the epididymal transit and is potentially involved in sperm binding to the zona pellucida. Journal of Cellular Physiology 227 3876-3886. (https://doi.org/10.1002/jcp.24099)

Caballero JN, Frenette G, Belleannee C \& Sullivan R 2013 CD9positive microvesicles mediate the transfer of molecules to bovine spermatozoa during epididymal maturation. PLOS ONE 8 e65364. (https://doi.org/10.1371/journal.pone.0065364)

Chabory E, Damon C, Lenoir A, Kauselmann G, Kern H, Zevnik B, Garrel C, Saez F, Cadet R, Henry-Berger J, et al. 2009 Epididymis seleno-independent glutathione peroxidase 5 maintains sperm DNA integrity in mice. Journal of Clinical Investigation 119 2074-2085. (https://doi.org/10.1172/JCI38940)

Chan JC, Morgan CP, Adrian Leu N, Shetty A, Cisse YM, Nugent BM, Morrison KE, Jašarević E, Huang W, Kanyuch $\mathbf{N}$, et al. 2020 Reproductive tract extracellular vesicles are sufficient to transmit intergenerational stress and program neurodevelopment. Nature Communications 11 1499. (https://doi.org/10.1038/s41467-02015305-w)

Chao MP, Takimoto CH, Feng DD, Mckenna K, Gip P, Liu J, Volkmer JP, Weissman IL \& Majeti R 2019 Therapeutic targeting of the macrophage immune checkpoint CD47 in myeloid malignancies. Frontiers in Oncology 9 1380. (https://doi.org/10.3389/ fonc.2019.01380)

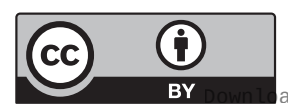


Chen Q, Yan W \& Duan E 2016 Epigenetic inheritance of acquired traits through sperm RNAs and sperm RNA modifications. Nature Reviews: Genetics 17 733-743. (https://doi.org/10.1038/nrg.2016.106)

Clement P \& Giuliano F 2015a Anatomy and physiology of genital organs - men. Handbook of Clinical Neurology 130 19-37. (https://doi. org/10.1016/B978-0-444-63247-0.00003-1)

Clement P \& Giuliano F 2015 $b$ Chapter 3 - Anatomy and physiology of genital organs - men. In Handbook of Clinical Neurology. Eds DB Vodušek \& F Boller. Elsevier. (https://doi.org/10.1016/B978-0-44463247-0.00003-1)

da Silveira JC, Veeramachaneni DN, Winger QA, Carnevale EM \& Bouma GJ 2012 Cell-secreted vesicles in equine ovarian follicular fluid contain miRNAs and proteins: a possible new form of cell communication within the ovarian follicle. Biology of Reproduction $\mathbf{8 6}$ 71. (https://doi.org/10.1095/biolreprod.111.093252)

D'Amours O, Bordeleau LJ, Frenette G, Blondin P, Leclerc P \& Sullivan R 2012a Binder of sperm 1 and epididymal sperm binding protein 1 are associated with different bull sperm subpopulations. Reproduction 143 759-771. (https://doi.org/10.1530/REP-11-0392)

D'Amours O, Frenette G, Bordeleau LJ, Allard N, Leclerc P, Blondin P \& Sullivan R $2012 b$ Epididymosomes transfer epididymal sperm binding protein 1 (ELSPBP1) to dead spermatozoa during epididymal transit in bovine. Biology of Reproduction 8794. (https://doi.org/10.1095/biolreprod.112.100990)

de Jong OG, Kooijmans SAA, Murphy DE, Jiang L, Evers MJW, Sluijter JPG, Vader P \& Schiffelers RM 2019 Drug delivery with extracellular vesicles: from imagination to innovation. Accounts of Chemical Research 52 1761-1770. (https://doi.org/10.1021/acs. accounts.9b00109)

Eickhoff R, Wilhelm B, Renneberg H, Wennemuth G, Bacher M, Linder D, Bucala R, Seitz J \& Meinhardt A 2001 Purification and characterization of macrophage migration inhibitory factor as a secretory protein from rat epididymis: evidences for alternative release and transfer to spermatozoa. Molecular Medicine 7 27-35. (https://doi. org/10.1007/BF03401836)

Eickhoff R, Baldauf C, Koyro HW, Wennemuth G, Suga Y, Seitz J, Henkel R \& Meinhardt A 2004 Influence of macrophage migration inhibitory factor (MIF) on the zinc content and redox state of proteinbound sulphydryl groups in rat sperm: indications for a new role of MIF in sperm maturation. Molecular Human Reproduction 10 605-611. (https://doi.org/10.1093/molehr/gah075)

Eickhoff R, Jennemann G, Hoffbauer G, Schuring MP, Kaltner H, Sinowatz F, Gabius HJ \& Seitz J 2006 Immunohistochemical detection of macrophage migration inhibitory factor in fetal and adult bovine epididymis: release by the apocrine secretion mode? Cells, Tissues, Organs 182 22-31. (https://doi.org/10.1159/000091715)

Ekhlasi-Hundrieser M, Schäfer B, Philipp U, Kuiper H, Leeb T, Mehta M, Kirchhoff C \& Töpfer-Petersen E 2007 Sperm-binding fibronectin type II-module proteins are genetically linked and functionally related. Gene 392 253-265. (https://doi.org/10.1016/j. gene.2007.01.002)

Fraser LR 2010 The 'switching on' of mammalian spermatozoa: molecular events involved in promotion and regulation of capacitation. Molecular Reproduction and Development 77 197-208. (https://doi. org/10.1002/mrd.21124)

Frenette G, Lessard C \& Sullivan R 2002 Selected proteins of 'prostasome-like particles' from epididymal cauda fluid are transferred to epididymal caput spermatozoa in bull. Biology of Reproduction $\mathbf{6 7}$ 308-313. (https://doi.org/10.1095/biolreprod67.1.308)

Frenette G, Girouard J, D'Amours O, Allard N, Tessier L \& Sullivan R 2010 Characterization of two distinct populations of epididymosomes collected in the intraluminal compartment of the bovine cauda epididymis. Biology of Reproduction 83 473-480. (https:// doi.org/10.1095/biolreprod.109.082438)

Gapp K, Jawaid A, Sarkies P, Bohacek J, Pelczar P, Prados J, Farinelli L, Miska E \& Mansuy IM 2014 Implication of sperm RNAs in transgenerational inheritance of the effects of early trauma in mice. Nature Neuroscience 17 667-669. (https://doi.org/10.1038/nn.3695)

Gatti JL, Métayer S, Belghazi M, Dacheux FO \& Dacheux JL 2005 Identification, proteomic profiling, and origin of ram epididymal fluid exosome-like vesicles. Biology of Reproduction 72 1452-1465. (https:// doi.org/10.1095/biolreprod.104.036426)

Gervasi MG \& Visconti PE 2017 Molecular changes and signaling events occurring in spermatozoa during epididymal maturation. Andrology 5 204-218. (https://doi.org/10.1111/andr.12320)

Gervasi MG, Soler AJ, González-Fernández L, Alves MG, Oliveira PF \& Martín-Hidalgo D 2020 Extracellular vesicles, the road toward the improvement of ART outcomes. Animals $\mathbf{1 0} 2171$ (https://doi.org/10.3390/ani10112171)

Girouard J, Frenette G \& Sullivan R 2011 Comparative proteome and lipid profiles of bovine epididymosomes collected in the intraluminal compartment of the caput and cauda epididymidis. International Journal of Andrology 34 e475-e486. (https://doi.org/10.1111/j.13652605.2011.01203.x)

Griffiths GS, Galileo DS, Reese K \& Martin-DeLeon PA 2008 Investigating the role of murine epididymosomes and uterosomes in GPI-linked protein transfer to sperm using SPAM1 as a model. Molecular Reproduction and Development 75 1627-1636. (https://doi. org/10.1002/mrd.20907)

Grigor'Eva A, Dyrkheeva N, Bryzgunova O, Tamkovich S, Chelobanov B \& Ryabchikova E 2017 Contamination of exosome preparations, isolated from biological fluids. Biochemistry (Moscow), Supplement Series B: Biomedical Chemistry 11 265-271.

Gui Y, Liu H, Zhang L, Lv W \& Hu X 2015 Altered microRNA profiles in cerebrospinal fluid exosome in Parkinson disease and Alzheimer disease. Oncotarget 6 37043-37053. (https://doi.org/10.18632/ oncotarget.6158)

Guo Y, Ji X, Liu J, Fan D, Zhou Q, Chen C, Wang W, Wang G, Wang H, YUAN W, et al. 2019 Effects of exosomes on pre-metastatic niche formation in tumors. Molecular Cancer 18 39. (https://doi. org/10.1186/s12943-019-0995-1)

Han L, Lam EWF \& Sun Y 2019 Extracellular vesicles in the tumor microenvironment: old stories, but new tales. Molecular Cancer 1859 (https://doi.org/10.1186/s12943-019-0980-8)

Han TT, Li W \& Li GP 2020 Progress in understanding the functional roles of extracellular vesicles in reproduction. Biomedical and Environmental Sciences 33 518-527. (https://doi.org/10.3967/ bes2020.068)

Hermo L \& Jacks D 2002 Nature's ingenuity: bypassing the classical secretory route via apocrine secretion. Molecular Reproduction and Development 63 394-410. (https://doi.org/10.1002/mrd.90023)

Höög JL \& Lötvall J 2015 Diversity of extracellular vesicles in human ejaculates revealed by cryo-electron microscopy. Journal of Extracellular Vesicles 4 28680-28680. (https://doi.org/10.3402/jev.v4.28680)

Hung WT, Navakanitworakul R, Khan T, Zhang P, Davis JS, Mcginnis LK \& Christenson LK 2017 Stage-specific follicular extracellular vesicle uptake and regulation of bovine granulosa cell proliferation. Biology of Reproduction 97 644-655. (https://doi. org/10.1093/biolre/iox106)

Jodar M, Soler-Ventura A, Oliva R \& Molecular Biology of Reproduction and Development Research Group 2017 Semen proteomics and male infertility. Journal of Proteomics 162 125-134. (https://doi.org/10.1016/j.jprot.2016.08.018)

Johnstone RM, ADAM M, Hammond JR, Orr L \& Turbide C 1987 Vesicle formation during reticulocyte maturation. Association of plasma membrane activities with released vesicles (exosomes). Journal of Biological Chemistry 262 9412-9420. (https://doi.org/10.1016/S00219258(18)48095-7)

Keller S, Rupp C, Stoeck A, Runz S, Fogel M, Lugert S, Hager HD, Abdel-Bakky MS, Gutwein P \& Altevogt P 2007 CD24 is a marker of exosomes secreted into urine and amniotic fluid. Kidney International 72 1095-1102. (https://doi.org/10.1038/sj.ki.5002486)

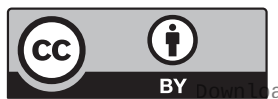

This work is licensed under a Creative Commons Attribution 4.0 International License. 
Kostereva N \& Hofmann MC 2008 Regulation of the spermatogonial stem cell niche. Reproduction in Domestic Animals 43 386-392. (https:// doi.org/10.1111/j.1439-0531.2008.01189.x)

Krapf D, Ruan YC, Wertheimer EV, Battistone MA, Pawlak JB, Sanjay A, Pilder SH, Cuasnicu P, Breton S \& Visconti PE 2012 cSrc is necessary for epididymal development and is incorporated into sperm during epididymal transit. Developmental Biology 369 43-53. (https://doi.org/10.1016/j.ydbio.2012.06.017)

Kravets FG, Lee J, Singh B, Trocchia A, Pentyala SN \& Khan SA 2000 Prostasomes: current concepts. Prostate $\mathbf{4 3}$ 169-174. (https://doi. org/10.1002/(sici)1097-0045(20000515)43:3<169::aid-pros2>3.0.co;2-d)

Laurenzana I, Lamorte D, Trino S, De Luca L, Ambrosino C, Zoppoli P, Ruggieri V, Del Vecchio L, Musto P, Caivano A et al. 2018 Extracellular vesicles: a new prospective in crosstalk between microenvironment and stem cells in hematological malignancies. Stem Cells International 2018 9863194. (https://doi. org/10.1155/2018/9863194)

Légaré C, Bérubé B, Boué F, Lefièvre L, Morales CR, El-Alfy M \& Sullivan R 1999 Hamster sperm antigen P26h is a phosphatidylinositol-anchored protein. Molecular Reproduction and Development 52 225-233. (https://doi.org/10.1002/(SICI)10982795(199902)52:2<225::AID-MRD14>3.0.CO;2-M)

Lin Y, Liang A, He Y, Li Z, Li Z, Wang G \& Sun F 2019 Proteomic analysis of seminal extracellular vesicle proteins involved in asthenozoospermia by iTRAQ. Molecular Reproduction and Development 86 1094-1105. (https://doi.org/10.1002/mrd.23224)

Llorente A, De Marco MC \& Alonso MA 2004 Caveolin-1 and MAL are located on prostasomes secreted by the prostate cancer PC-3 cell line. Journal of Cell Science 117 5343-5351. (https://doi.org/10.1242/ jcs.01420)

Llorente A, Van Deurs B \& Sandvig K 2007 Cholesterol regulates prostasome release from secretory lysosomes in PC-3 human prostate cancer cells. European Journal of Cell Biology 86 405-415. (https://doi. org/10.1016/j.ejcb.2007.05.001)

Machtinger R, Laurent LC \& Baccarelli AA 2016 Extracellular vesicles: roles in gamete maturation, fertilization and embryo implantation. Human Reproduction Update 22 182-193. (https://doi. org/10.1093/humupd/dmv055)

Maciel E \& Mansuy IM 2019 Extracellular vesicles and their miRNA cargo: a means of communication between soma and germline in the mammalian reproductive system. Chimia 73 356-361. (https://doi. org/10.2533/chimia.2019.356)

Manin M, Lecher P, Martinez A, Tournadre S \& Jean C 1995 Exportation of mouse vas deferens protein, a protein without a signal peptide, from mouse vas deferens epithelium: a model of apocrine secretion. Biology of Reproduction 52 50-62. (https://doi.org/10.1095/ biolreprod52.1.50)

Martin-DeLeon PA 2006 Epididymal SPAM1 and its impact on sperm function. Molecular and Cellular Endocrinology 250 114-121. (https:// doi.org/10.1016/j.mce.2005.12.033)

Martin-DeLeon PA 2016 Uterosomes: exosomal cargo during the estrus cycle and interaction with sperm. Frontiers in Bioscience 8 115-122. (https://doi.org/10.2741/s451)

Marty MS, Chapin RE, Parks LG \& Thorsrud BA 2003 Development and maturation of the male reproductive system. Birth Defects Research: Part B, Developmental and Reproductive Toxicology 68 125-136. (https:// doi.org/10.1002/bdrb.10015)

Mathivanan S, Ji H \& Simpson RJ 2010 Exosomes: extracellular organelles important in intercellular communication. Journal of Proteomics 73 1907-1920. (https://doi.org/10.1016/j.jprot.2010.06.006)

Mause SF \& Weber C 2010 Microparticles: protagonists of a nove communication network for intercellular information exchange. Circulation Research 107 1047-1057. (https://doi.org/10.1161/ CIRCRESAHA.110.226456)

Mittal S, Gupta P, Chaluvally-Raghavan P \& Pradeep S 2020 Emerging role of extracellular vesicles in immune regulation and cancer progression. Cancers 12 3563. (https://doi.org/10.3390/ cancers12123563)

Murdica V, Giacomini E, Makieva S, Zarovni N, Candiani M, Salonia A, Vago R \& Viganò P 2020 In vitro cultured human endometrial cells release extracellular vesicles that can be uptaken by spermatozoa. Scientific Reports 10 8856. (https://doi.org/10.1038/ s41598-020-65517-9)

Nef S, Stévant I \& Greenfield A 2019 Characterizing the bipotential mammalian gonad. Current Topics in Developmental Biology 134 167-194. (https://doi.org/10.1016/bs.ctdb.2019.01.002)

Nixon B, De Iuliis GN, Hart HM, Zhou W, Mathe A, Bernstein IR, Anderson AL, Stanger SJ, Skerrett-Byrne DA, Jamaluddin MFB, et al. 2019 Proteomic profiling of mouse epididymosomes reveals their contributions to post-testicular sperm maturation. Molecular and Cellular Proteomics 18 S91-S108. (https:// doi.org/10.1074/mcp.RA118.000946)

Ochoa-Bernal MA \& Fazleabas AT 2020 Physiologic events of embryo implantation and decidualization in human and non-human primates. International Journal of Molecular Sciences 21 1973. (https:// doi.org/10.3390/ijms21061973)

Oh JS, Han C \& Cho C 2009 ADAM7 is associated with epididymosomes and integrated into sperm plasma membrane. Molecules and Cells $\mathbf{2 8}$ 441-446. (https://doi.org/10.1007/s10059-009-0140-x)

Olson GE, Winfrey VP, Nagdas SK \& Melner MH 2004 Region-specific expression and secretion of the fibrinogen-related protein, fgl2, by epithelial cells of the hamster epididymis and its role in disposal of defective spermatozoa. Journal of Biological Chemistry 279 51266-51274. (https://doi.org/10.1074/jbc.M410485200)

O'neill CP, Gilligan KE \& Dwyer RM 2019 Role of extracellular vesicles (EVs) in cell stress response and resistance to cancer therapy. Cancers 11 136. (https://doi.org/10.3390/cancers11020136)

Oszvald Á, Szvicsek Z, Sándor Go, Kelemen A, Soós AÁ, Pálóczi K, Bursics A, Dede K, Tölgyes T, Buzás EI, et al. 2020 Extracellular vesicles transmit epithelial growth factor activity in the intestinal stem cell niche. Stem Cells 38 291-300. (https://doi.org/10.1002/stem.3113)

Park KH, Kim BJ, Kang J, Nam TS, Lim JM, Kim HT, Park JK, Kim YG, Chae SW \& Kim UH $2011 \mathrm{Ca} 2+$ signaling tools acquired from prostasomes are required for progesterone-induced sperm motility. Science Signaling 4 ra31. (https://doi.org/10.1126/ scisignal.2001595)

Pisitkun T, Shen RF \& Knepper MA 2004 Identification and proteomic profiling of exosomes in human urine. PNAS 101 13368-13373. (https://doi.org/10.1073/pnas.0403453101)

Plante G, Prud'homme B, Fan J, Lafleur M \& Manjunath P 2016 Evolution and function of mammalian binder of sperm proteins. Cell and Tissue Research 363 105-127.

Pons-Rejraji H, Artonne C, Sion B, Brugnon F, Canis M, Janny L \& Grizard G 2011 Prostasomes: inhibitors of capacitation and modulators of cellular signalling in human sperm. International Journal of Andrology 34 568-580. (https://doi.org/10.1111/j.13652605.2010.01116.x)

Poon IKH, Gregory CD \& Kaparakis-Liaskos M 2018. Editorial: The immunomodulatory properties of extracellular vesicles from pathogens, immune cells, and non-immune cells. Frontiers in Immunology 9 3024. (https://doi.org/10.3389/fimmu.2018.03024)

Qu P, Luo S, Du Y, Zhang Y, Song X, Yuan X, Lin Z, Li Y \& Liu E 2020 Extracellular vesicles and melatonin benefit embryonic develop by regulating reactive oxygen species and 5-methylcytosine. Journal of Pineal Research 68 e12635. (https://doi.org/10.1111/jpi.12635)

Rappa G, Santos MF, Green TM, Karbanová J, Hassler J, Bai Y, Barsky SH, Corbeil D \& Lorico A 2017 Nuclear transport of cancer extracellular vesicle-derived biomaterials through nuclear envelope invagination-associated late endosomes. Oncotarget 8 14443-14461. (https://doi.org/10.18632/oncotarget.14804)

Riches A, Powis S, Mullen P, Harrison D, Hacker C, Lucocq J, Bowness J, Chapman A, Cameron R, Mclornan L, et al. 2016

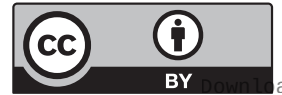

This work is licensed under a Creative Commons Attribution 4.0 International License. 
Human urinary exosomes in bladder cancer patients: properties, concentrations and possible clinical application. Bladder 3 e19. (https://doi.org/10.14440/bladder.2016.63)

Robertson SA, Guerin LR, Moldenhauer LM \& Hayball JD 2009 Activating T regulatory cells for tolerance in early pregnancy - the contribution of seminal fluid. Journal of Reproductive Immunology $\mathbf{8 3}$ 109-116. (https://doi.org/10.1016/j.jri.2009.08.003)

Rodriguez-Caro H, Dragovic R, Shen M, Dombi E, Mounce G, Field K, Meadows J, Turner K, Lunn D, Child T, et al. 2019 In vitro decidualisation of human endometrial stromal cells is enhanced by seminal fluid extracellular vesicles. Journal of Extracellular Vesicles $\mathbf{8}$ 1565262. (https://doi.org/10.1080/20013078.2019.1565262)

Ronquist G \& Brody I 1985 The prostasome: its secretion and function in man. Biochimica et Biophysica Acta 822 203-218. (https://doi. org/10.1016/0304-4157(85)90008-5)

Ronquist G \& Nilsson BO 2004 The Janus-faced nature of prostasomes: their pluripotency favours the normal reproductive process and malignant prostate growth. Prostate Cancer and Prostatic Diseases 7 21-31. (https://doi.org/10.1038/sj.pcan.4500684)

Ronquist G, Brody I, Gottfries A \& Stegmayr B 1978a An $\mathrm{Mg} 2+$ and Ca2+-stimulated adenosine triphosphatase in human prostatic fluid - Part II. Andrologia 10 427-433. (https://doi. org/10.1111/j.1439-0272.1978.tb03064.x)

Ronquist G, Brody I, Gottfries A \& Stegmayr B 1978b An $\mathrm{Mg} 2+$ and Ca2+-stimulated adenosine triphosphatase in human prostatic fluid: Part I. Andrologia 10 261-272. (https://doi. $\operatorname{org} / 10.1111 / \mathrm{j} .1439-0272.1978 . t b 03030 . x)$

Rooney IA, Atkinson JP, Krul ES, Schonfeld G, Polakoski K, Saffitz JE \& Morgan BP 1993 Physiologic relevance of the membrane attack complex inhibitory protein CD59 in human seminal plasma: CD59 is present on extracellular organelles (prostasomes), binds cell membranes, and inhibits complement-mediated lysis. Journal of Experimental Medicine 177 1409-1420. (https://doi. org/10.1084/jem.177.5.1409)

Rowlison T, Cleland TP, Ottinger MA \& Comizzoli P 2020 Novel proteomic profiling of epididymal extracellular vesicles in the domestic cat reveals proteins related to sequential sperm maturation with differences observed between normospermic and teratospermic individuals. Molecular and Cellular Proteomics 19 2090-2104. (https:// doi.org/10.1074/mcp.RA120.002251)

Saalmann A, Münz S, Ellerbrock K, Ivell R \& Kirchhoff C 2001 Novel sperm-binding proteins of epididymal origin contain four fibronectin type II-modules. Molecular Reproduction and Development 58 88-100. (https://doi.org/10.1002/1098-2795(200101)58:1<88::AIDMRD12>3.0.CO;2-D)

Sahlén GE, Egevad L, Ahlander A, Norlén BJ, Ronquist G \& Nilsson BO 2002 Ultrastructure of the secretion of prostasomes from benign and malignant epithelial cells in the prostate. Prostate $\mathbf{5 3}$ 192-199. (https://doi.org/10.1002/pros.10126)

Sahlén G, Nilsson O, Larsson A, Carlsson L, Norlén BJ \& Ronquist G 2010 Secretions from seminal vesicles lack characteristic markers for prostasomes. Upsala Journal of Medical Sciences $\mathbf{1 1 5}$ 107-112. (https://doi.org/10.3109/03009730903366067)

Samanta L, Swain N, Ayaz A, Venugopal V \& Agarwal A 2016 Post-translational modifications in sperm proteome: the chemistry of proteome diversifications in the pathophysiology of male factor infertility. Biochimica et Biophysica Acta 1860 1450-1465. (https://doi. $\operatorname{org} / 10.1016 /$ j.bbagen.2016.04.001)

Schwarz A, Wennemuth G, Post H, Brandenburger T, Aumuller G \& Wilhelm B 2013 Vesicular transfer of membrane components to bovine epididymal spermatozoa. Cell and Tissue Research 353 549-561. (https://doi.org/10.1007/s00441-013-1633-7)

Sharkey DJ, Tremellen KP, Jasper MJ, Gemzell-Danielsson K \& Robertson SA 2012 Seminal fluid induces leukocyte recruitment and cytokine and chemokine mRNA expression in the human cervix after coitus. Journal of Immunology 188 2445-2454. (https://doi. org/10.4049/jimmunol.1102736)

Skibinski G, Kelly RW, Harkiss D \& James K 1992

Immunosuppression by human seminal plasma - extracellular organelles (prostasomes) modulate activity of phagocytic cells. American Journal of Reproductive Immunology 28 97-103. (https://doi. org/10.1111/j.1600-0897.1992.tb00767.x)

Sullivan R 2016a Epididymosomes: role of extracellular microvesicles in sperm maturation. Frontiers in Bioscience 8 106-114. (https://doi. org/10.2741/s450)

Sullivan R \& Saez F 2013 Epididymosomes, prostasomes, and liposomes: their roles in mammalian male reproductive physiology. Reproduction 146 R21-R35. (https://doi.org/10.1530/REP-13-0058)

Sullivan R, Saez F, Girouard J \& Frenette G 2005 Role of exosomes in sperm maturation during the transit along the male reproductive tract. Blood Cells, Molecules and Diseases 35 1-10. (https://doi. org/10.1016/j.bcmd.2005.03.005)

Sullivan R, Frenette G \& Girouard J 2007 Epididymosomes are involved in the acquisition of new sperm proteins during epididymal transit. Asian Journal of Andrology 9 483-491. (https://doi.org/10.1111/ j.1745-7262.2007.00281.x)

Suryawanshi AR, Khan SA, Joshi CS \& Khole VV 2012 Epididymosome-mediated acquisition of MMSDH, an androgendependent and developmentally regulated epididymal sperm protein. Journal of Andrology 33 963-974. (https://doi.org/10.2164/ jandrol.111.014753)

Synowsky SA, Shirran SL, Cooke FGM, Antoniou AN, Botting CH \& Powis SJ 2017 The major histocompatibility complex class I immunopeptidome of extracellular vesicles. Journal of Biological Chemistry 292 17084-17092. (https://doi.org/10.1074/jbc. M117.805895)

Tannetta D, Dragovic R, Alyahyaei Z \& Southcombe J 2014 Extracellular vesicles and reproduction-promotion of successful pregnancy. Cellular and Molecular Immunology 11 548-563. (https:// doi.org/10.1038/cmi.2014.42)

Tarazona R, Delgado E, Guarnizo MC, Roncero RG, Morgado S, Sanchez-Correa B, Gordillo JJ, Dejulian J \& Casado JG 2011 Human prostasomes express CD48 and interfere with NK cell function. Immunobiology 216 41-46. (https://doi.org/10.1016/j. imbio.2010.03.002)

Tarique I, Haseeb A, Bai X, Li W, Yang P, Huang Y, Yang S, Xu M, Zhang Y, Vistro WA, et al. 2020 Cellular evidence of CD63enriched exosomes and multivesicular bodies within the seminiferous tubule during the spermatogenesis of turtles. Microscopy and Microanalysis 26 148-156. (https://doi.org/10.1017/S1431927619015149)

Théry C, Witwer KW, Aikawa E, Alcaraz MJ, Anderson JD, Andriantsitohaina R, Antoniou A, Arab T, Archer F, Atkin-Smith GK, et al. 2018 Minimal information for studies of extracellular vesicles 2018 (MISEV2018): a position statement of the International Society for extracellular vesicles and update of the MISEV2014 guidelines. Journal of Extracellular Vesicles 71535750. (https://doi.org/10.1080/20013078.2018.1535750)

Thimon V, Frenette G, Saez F, Thabet M \& Sullivan R 2008 Protein composition of human epididymosomes collected during surgical vasectomy reversal: a proteomic and genomic approach. Human Reproduction 23 1698-1707. (https://doi.org/10.1093/humrep/den181)

Trigg NA, Eamens AL \& Nixon B 2019 The contribution of epididymosomes to the sperm small RNA profile. Reproduction $\mathbf{1 5 7}$ R209-R223. (https://doi.org/10.1530/REP-18-0480)

Turchinovich A, Drapkina o \& Tonevitsky A 2019 Transcriptome of extracellular vesicles: state-of-the-art. Frontiers in Immunology 10202. (https://doi.org/10.3389/fimmu.2019.00202)

Utleg AG, Yi EC, Xie T, Shannon P, White JT, Goodlett DR, Hood L \& Lin B 2003 Proteomic analysis of human prostasomes. Prostate 56 150-161. (https://doi.org/10.1002/pros.10255)

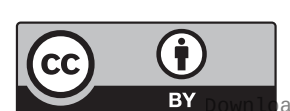

This work is licensed under a Creative Commons Attribution 4.0 International License. 
Valadi H, Ekstrom K, Bossios A, Sjostrand M, Lee JJ \& Lotvall JO 2007 Exosome-mediated transfer of mRNAs and microRNAs is a novel mechanism of genetic exchange between cells. Nature Cell Biology 9 654-659. (https://doi.org/10.1038/ncb1596)

Vasconcelos MH, Caires HR, Ābols A, Xavier CPR \& Linē A 2019 Extracellular vesicles as a novel source of biomarkers in liquid biopsies for monitoring cancer progression and drug resistance. Drug Resistance Updates 47 100647. (https://doi.org/10.1016/j.drup.2019.100647)

Vilanova-Perez T, Jones C, Balint S, Dragovic R, L Dustin M, Yeste M \& Coward K 2020 Exosomes derived from HEK293T cells interact in an efficient and noninvasive manner with mammalian sperm in vitro. Nanomedicine 15 1965-1980. (https://doi.org/10.2217/ nnm-2020-0056)

Vivacqua A, Siciliano L, Sabato M, Palma A \& Carpino A 2004 Prostasomes as zinc ligands in human seminal plasma. International Journal of Andrology 27 27-31. (https://doi.org/10.1111/j.13652605.2004.00441.x)

Weissgerber P, Kriebs U, Tsvilovskyy V, Olausson J, Kretz O, Stoerger C, Mannebach S, Wissenbach U, Vennekens R, Middendorff R, et al. 2012 Excision of Trpv6 gene leads to severe defects in epididymal Ca2+ absorption and male fertility much like single D541A pore mutation. Journal of Biological Chemistry 287 17930-17941. (https://doi.org/10.1074/jbc.M111.328286)

Witwer KW \& Théry C 2019 Extracellular vesicles or exosomes? On primacy, precision, and popularity influencing a choice of nomenclature. Journal of Extracellular Vesicles 8 1648167. (https://doi. org/10.1080/20013078.2019.1648167)

Yáñez-Mó M, Siljander PR, Andreu Z, Zavec AB, Borràs FE, Buzas EI, Buzas K, Casal E, Cappello F, Carvalho J, et al. 2015 Biological properties of extracellular vesicles and their physiological functions. Journal of Extracellular Vesicles 4 27066. (https://doi. org/10.3402/jev.v4.27066)

Yang C, Guo WB, Zhang WS, Bian J, Yang JK, Zhou QZ, Chen MK, Peng W, Qi T, Wang CY, et al. 2017 Comprehensive proteomics analysis of exosomes derived from human seminal plasma. Andrology $\mathbf{5}$ 1007-1015. (https://doi.org/10.1111/andr.12412)

Zhang X, Vos HR, Tao W \& Stoorvogel W 2020 Proteomic profiling of two distinct populations of extracellular vesicles isolated from human seminal plasma. International Journal of Molecular Sciences 217957. (https://doi.org/10.3390/ijms21217957)

Zhou X, Xie F, Wang L, Zhang L, Zhang S, Fang M \& Zhou F 2020 The function and clinical application of extracellular vesicles in innate immune regulation. Cellular and Molecular Immunology 17 323-334. (https://doi.org/10.1038/s41423-020-0391-1)

Received in final form 16 June 2021

Accepted 25 June 2021

Accepted Manuscript published online 25 June 2021 (c) 2021 The authors Published by Bioscientifica Ltd

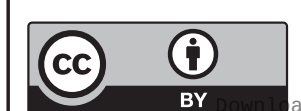

This work is licensed under a Creative Commons Attribution 4.0 International License. 